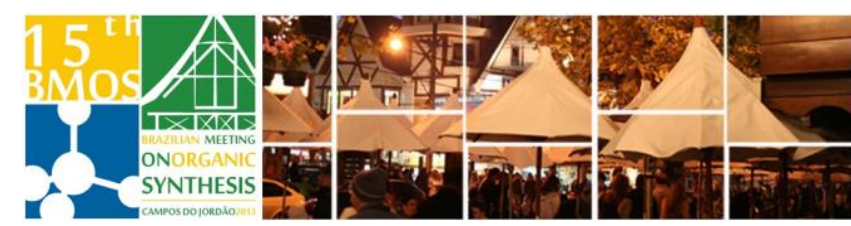

\title{
Synthesis of Polyketide Fragments in Order to Study the Elaiophylin Biosynthesis
}

\author{
Patrícia Prediger, ${ }^{1}$ Luiz Carlos Dias. ${ }^{1, *}$ \\ ${ }^{1}$ Instituto de Química, Universidade Estadual de Campinas, UNICAMP, C.P. 6154, 13084-971 Campinas, \\ $S P$, Brasil. \\ *e-mail ldias@iqm.unicamp.br
}

Keywords: elaiophylin, polyketide, aldol reaction

\section{INTRODUCTION}

Elaiophylin (1), a glycosidic polyketide, was first isolated from the cultures of Streptomyces melanosporus by Arcamone et al. $^{1 \mathrm{a}}$ and by Arai $^{1 \mathrm{~b}}$ from a related microorganism. Elaiophylin is a 16membered macrolide which displays a wide range of bioactivities such as antimicrobial, cell cycle inhibition, apoptosis induction, immunosuppressive, anthelmintic, inhibition of $\mathrm{K}^{+}$-dependent adenosine triphosphatases, and plant growth inhibition. ${ }^{2}$

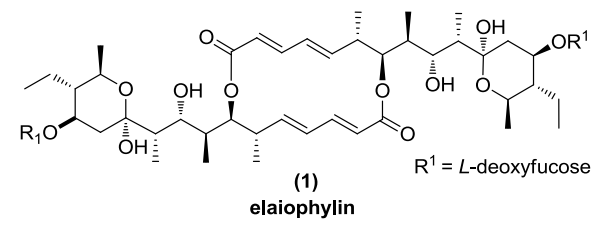

Figure 1. Elaiophylin (1).

Due to the pronounced activity showed by this macrolide, we are interested in to investigate its biosynthesis by analyzing the interaction between the elaiophylin enzyme thioesterase and the fragments $2-5^{3}$
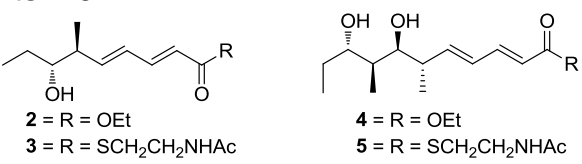

Figure 2. Fragments for studying elaiophylin biosynthesis.

\section{RESULTS AND DISCUSSION}

We started our synthesis with an Evans' asymmetric aldol reaction of chiral crotonate imide 6 and propionaldehyde (Scheme 1). The syn aldol adduct 7 was obtained in good yield with >95:5 diastereoselectivity. Reductive removal of the chiral auxiliary with $\mathrm{LiBH}_{4}$, followed by diol protection, provided the acetal 8 in $93 \%$ yield for 2 steps. The selective reduction of $\mathbf{8}$ was carried out with DIBAL, furnishing the alcohol 9 in $99 \%$ yield. Tosylation of the hydroxyl group under standard conditions followed by reduction of the tosylate using $\mathrm{LiBH}_{4}$ gave 10 in the range of $65-85 \%$ yield. We then submitted 10 to the dihydroxylation/oxidative cleavage of the vinyl group, which provided aldehyde 11 in $86 \%$ yield for 2 steps. Thus, the HWE olefination with the phosphonocrotonate 12 was carried out to afford the E,E diene 13 in $84 \%$ yield. Finally, 13 was treated with DDQ for the oxidative deprotection in $66 \%$ yield.

$$
\text { 1) }
$$

Scheme 1. Synthesis of fragment 2.

Aiming the synthesis of fragment $\mathbf{3}$, the ester $\mathbf{1 3}$ was hydrolyzed and then submitted to the coupling reaction with the thioacetamide $\mathbf{1 4}$ in the presence of DCC and HOBt (Scheme 2). The thioester was obtained in $67 \%$ yield. DDQ oxidative deprotection provided the desired fragment 3 in $80 \%$ yield.

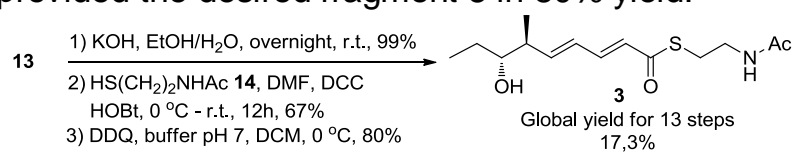

Scheme 2. Synthesis of fragment 3.

\section{CONCLUSION}

We successfully achieved the synthesis of two fragments which will be employed to study the elaiophylin biosynthesis.

\section{ACKNOWLEDGEMENTS}

FAPESP, CNPq and CAPES for financial support

\section{REFERENCES}

${ }^{1}$ (a) Arcamone, F. M.; Bertazzoli, C.; Ghione, M.; Scotti, T. G. G. Microbiol 1959, 7, 207. (b) Azalomycin, B.; Arai, M. J. Antibiot., Ser. A 1960, 13, 51. ${ }^{2}$ Hammann, P.; Kretzschmar, G.; Seibert, G. J. Antibiot., 1990, 43, 1431.

${ }^{3}$ The biological essays are in progress at University of Cambridge by Dr. Yongjun Zhou and Prof. Dr. Peter F. Leadlay. 